\title{
The relationship between nucleated Red Blood Cells (nRBCs) and length of hospital stay in the newborn period
}

\author{
Authors \\ Dr Babu K Joseph ${ }^{1}$, Dr Freena Rose ${ }^{2}$, Dr Tara Gopinatan ${ }^{3}$ \\ ${ }^{1}$ Assistant Professor, Dept of Pediatrics, ${ }^{2}$ Assistant Professor, Dept of Pathology, ${ }^{3}$ Senior Resident, Dept of \\ Pediatrics , Govt. Medical College Thrissur, Kerala \\ Corresponding Author \\ Dr Freena Rose \\ Assistant Professor, Dept of Pathology, Government Medical College, Thrissur, Kerala, Pin 680596 \\ Phone No: 9446551832, 0487 2204832, Email:freenarose@yahoo.com

\begin{abstract}
Nucleated red blood cells (nRBCs) in the peripheral smear of newborns are associated with a variety of foetal conditions like Hypoxic Ischemic Encephalopathy (HIE), prematurity, sepsis etc. All these conditions are related to a high morbidity, length of hospital stay and mortality.

Aim: To study the relationship between the number of nucleated RBC and the length of hospital stay.

Methods and Results: Peripheral smear of 162 babies admitted to the newborn nursery during the study period were studied for relationship between $n R B C s$ and length of hospital stay. The study population were categorised into three groups based on the length of hospital stay. The group 1 with less than 6 days of hospital stay, group 2 between 7 days and 14 days and group 3 with more than 14 days of hospital stay. The mean nRBCs count in group 1 was 4.28, in group 2 was 20 and in group 3 was 28.75. This was found to be statistically significant ( $p$ value $<0.001$ ).

Conclusion: The nRBCs in the newborn period can be used to predict the length of hospital stay.

Keywords: Nucleated red blood cells, newborn, length of hospital stay.
\end{abstract}

\section{Introduction}

In 1924, Lippman ${ }^{1}$ reported nRBCs in the blood of newborns in the first day of life. They are primarily produced in the foetal bone marrow in response to erythropoietin, which in turn is increased in different types of stress in the newborn period. Many acute and chronic stressful conditions increase the number of circulating nRBCs by two mechanisms, either by increased erythropoietic activity (mediated by the erythropoietin release) or by a sudden release from the marrow storage pools
The mean value of nRBCs in the first day of life in healthy term newborns is about $500 \mathrm{nRBCs} /$ $\mathrm{mm} 3$, (0-10 nRBCs/ $100 \mathrm{WBCs})$ and values above $1000 \mathrm{nRBCs} / \mathrm{mm} 3(10-20 \mathrm{nRBCs} / \mathrm{WBC})$ is considered elevated ${ }^{2}$.

Studies have consistently shown decreasing $\mathrm{nRBCs}$ as the gestational age increases, except that post-term infants have higher counts than term infants ${ }^{\mathbf{3 , 4 , 5}}$. Small premature newborns may normally have up to $10000 \mathrm{nRBCs} / \mathrm{mm} 3$. In the normal neonate, nRBCs are rapidly cleared from 
the bloodstream after birth ${ }^{1,6}$. By 12 hours of age, the counts fall by about $50 \%$, and by 48 hours only $20-30 \mathrm{nRBCs} / \mathrm{mm} 3$ are found. In healthy term newborns, virtually no nRBCs are found after the third or fourth day of life, although they may persist in small numbers up to 1 week in preterm newborns ${ }^{3,7}$.

Nucleated red blood cells (nRBC), in peripheral blood is associated with a variety of foetal conditions like HIE, sepsis, prematurity, eclampsia and pre-eclampsia etc. These conditions have a direct relationship to the morbidity, length of hospital stay and mortality. As the NICU admissions are costly and require huge amounts of financial and manpower resources, it is prudent to calculate expected length of admission in the newborn ICU.

\section{Elevated $\mathrm{nRBC}$ count in the newborn period}

Increased number of circulating $\mathrm{nRBCs}$ are seen in association with long standing erythropoietin induced erythropoiesis, acute stress mediated release of normoblasts from the marrow, postnatal hypoxia, and in neonates with idiopathic increase.

Significance of $\mathrm{nRBC}$ in the newborn period

Nucleated red blood cells (nRBCs) are fetal/neonatal hematologic markers for placental dysfunction, hypoxemia, and asphyxia as well as any type of stress in the newborn period. $\mathbf{n R B C}$ count elevation at birth and its persistence is linked statistically to adverse outcome, ${ }^{8}$

It was found that low birth weight, low Apgar scores, sepsis, need for respiratory support, abnormal brain ultrasound findings, morbidity rate and adverse neonatal outcome were significantly higher in babies with higher $\mathbf{n R B C}$ count $^{9}$

An elevated nucleated red blood cell (nRBC) count is an independent risk factor for postnatal bleeding complications in growth-restricted infants ${ }^{10}$ Nucleated RBC count can be used as an early marker of severity of birth asphyxia , and may be useful to predict the neurological outcome in asphyxiated babies ${ }^{11,12}$
Table 1: Differential diagnosis of increased nRBCs in the foetus and newborn

\begin{tabular}{|ll|}
\hline$\bullet$ & Acute and Subacute hypoxia \\
\hline$\bullet$ & Blood loss \\
\hline$\bullet$ & Down's syndrome \\
\hline$\bullet$ & Maternal pre-eclampsia \\
\hline$\bullet$ & Anaemia \\
\hline$\bullet$ & Chronic hypoxia \\
\hline$\bullet$ & Haemolysis-ABO or Rh isoimmunization, \\
& other immune hemolysis \\
\hline$\bullet$ & Maternal diabetes \\
\hline$\bullet$ & Post-term newborns \\
\hline$\bullet$ & Down's syndrome \\
\hline$\bullet$ & TORCH infections \\
\hline$\bullet$ & Chorioamnionitis \\
\hline$\bullet$ & Cyanotic heart disease \\
\hline$\bullet$ & Pulmonary failure \\
\hline
\end{tabular}

\section{Other predictors of neonatal outcome}

There are a few laboratory tests like the CRP which will give the highest negative predictive value for diagnosing neonatal sepsis (NNS) ${ }^{\mathbf{1 3}}$. The BNP is a cardiac injury marker ${ }^{\mathbf{1 4}}$, and Neuronal Specific Enolase ${ }^{\mathbf{1 5}}$, is a marker for brain injury .But these markers are costly and has limited availability so that their use cannot be recommended as a universal predictive markers

\section{Methods}

The study group comprised of 162 newborns admitted in the new born intensive care unit of government medical college, Thrissur during the study period

Venous blood samples were collected, between 1 hour and 36 hours of life, and $\mathrm{nRBC}$ count as the percentage of white blood cells (WBC) in peripheral blood smear, was determined from the pathology department. The counting was done by a qualified and experienced senior pathologist from the same department

\section{Analytical methods}

The babies were divided into three groups based on the length of hospital stay. Group 1comprising babies who were discharged within 6days of NICU stay, group 2 between 7 to 14 days and group 3 with more than 15 days. 


\section{JMSCR Vol||05||Issue||09||Page 28356-28359||September}

The nucleated RBC counts (nRBC) in these three groups were compared and analysed for any correlation between the nRBC count and the length of hospital stay. Analysis was done using R software version 3.2.3.

\section{Observation and Results}

The total number of babies was 162; The number of babies in Gp 1 was 82, in Gp 2 was 52 and in Gp 3 was 22 .

Table 2: Categorisation according to gestational age $(n=162)$

\begin{tabular}{|l|c|}
\hline term & 130 \\
\hline preterm & 32 \\
\hline Total & 162 \\
\hline
\end{tabular}

The mean length of hospital stay in the first group was 3.9 days, in Gp2 it was 8.83 days, and 21.64 days in $\mathrm{Gp} 3$

Table 3: Mean hospital stay in 3 groups

\begin{tabular}{|l|c|c|c|}
\hline & Gp 1 & Gp2 & Gp3 \\
\hline No of babies & 88 & 52 & 22 \\
\hline Mean & 3.9 & 8.83 & 21.64 \\
\hline Std deviation & 1.119 & 1.855 & 4.756 \\
\hline Min & 2 & 7 & 16 \\
\hline $\max$ & 6 & 13 & 29 \\
\hline
\end{tabular}

The mean nRBCs count in group I was $4.28 / 100$ WBC, as compared to $20 / 100 \mathrm{WBC}$ in Gp 2 and $28.75 / 100 \mathrm{WBC}$ in the Gp 3.

Table $4:$ nRBC count in 3 groups

\begin{tabular}{|l|c|c|c|}
\hline & $\begin{array}{c}\text { Gp1(<6 } \\
\text { d) }\end{array}$ & Gp2(7-14d) & $\begin{array}{c}\text { Gp3(>14 } \\
\text { d) }\end{array}$ \\
\hline No of babies & 88 & 52 & 22 \\
\hline $\begin{array}{l}\text { Mean nRBCs } \\
\text { count }\end{array}$ & 4.28 & 20 & 28.75 \\
\hline Std. Deviation & 7.64 & 5.804 & 3.897 \\
\hline Minimum & 0 & 12 & 22 \\
\hline Maximum & 30 & 33 & 37 \\
\hline
\end{tabular}

When the correlation was analysed using KruskalWallis Test (as the number of hospital stay in the three groups is a qualitative variable and the number of nRBCs is a quantitative variable and both were not following normalcy), the correlation was found to be significant and the $\mathrm{p}$ value was found to be $<0.001$

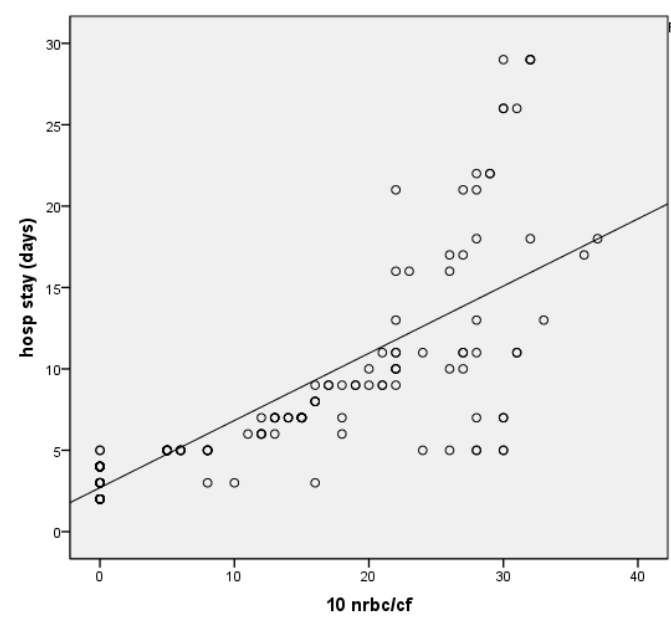

Figure 1: Scatter plot of nRBCs vs. length of hospital stay

When the whole population was analysed the Spearman's rho was 0.974 and the $\mathrm{p}$ Value was $<0.001$.

\section{Discussion}

Admission into the newborn ICU is costly, both financially as well as in terms of human work hours. The running cost of NICU care per patient per day was Rs 5450 (US\$ 125). NICU rent and ancillary personnel salary comprised the largest proportion of the running costs. Estimated expense for the care for a baby $<1000$ grams was Rs. 1,68,000, Rs. 88,300 for babies 1000-1250 g. and Rs. 41,700 for those between $1250-1500 \mathrm{~g}$. The average daily expenses being around Rs5000 .${ }^{16}$ It is also a stressful occasion to the concerned parents as well as the caregivers. As the length of ICU admission increases, the burden of the parents as well as the caregivers also increases. Most of the NICU admission are for prematurity, birth asphyxia, neonatal jaundice, and neonatal septicaemia. All these conditions are associated with increased number of nRBCs in the peripheral smear. This is our attempt to find out, the relationship between the length of NICU stay and the number of nRBCs in the peripheral smear. As seen from our results there is a positive correlation between nRBCs and the length of hospital stay. This will help us to brief the parents regarding the expected length of hospital stay. This will definitely prime the parents in advance regarding 
the situation of their babies. This will help to prevent many future allegations of malpractice and negligence.

\section{Conclusions}

The determination of nRBC count can be used as a predictive marker for the expected length of hospital stay in the newborn period.

\section{References}

1. Lippman HS. Morphologic and quantitative study of blood corpuscles in the newborn period. American Journal of Diseases in Children 1924;27:473-515.

2. Manroe BL, Weinberg AG, Rosenfeld CR, et al. The neonatal blood count in health and disease. I. Reference values for neutrophilic cells. J Pediatr 1979;95:8998.

3. Green DW, Hendon B, Mimouni FB. Nucleated erythrocytes an intraventricular hemorrhage in preterm neonates. Pediatrics 1995;96:475-8.

4. Buonocore G, Perrone S, Gioia D, et al. Nucleated red blood cell count at birth as an index of perinatal brain damage. Am J Obstet Gynecol 1999;181:1500-5.

5. Axt R, Ertan K, Hendrik J, et al. Nucleated red blood cells in cord blood of singleton term and post-term neonates. J Perinat Med 1999;27:376-18.

6. Green DW, Mimouni G. Nucleated erythrocytes in healthy infants and in infants of diabetic mothers. J Pediatr 1990;166:129-31.

7. Oski FA, Naiman JL. Normal blood values in the newborn period. In: Hematologic problems in the newborn. 2nd ed. Philadelphia: WB Saunders, 1972:1-30.

8. Ryerson CS, Sanes S. The age of pregnancy. Histologic diagnosis from percentage of erythroblasts in chorionic capillaries. Arch Pathol 1934;17:648-51.

9. Javert CT. The occurrence and significance of nucleated erythrocytes in the fetal vessels of the placenta. Am J Obstet Gynecol 1939;37:184-94.

10. Fox H. The incidence and significance of nucleated erythrocytes in the fetal vessels of the mature human placenta. J Obstet Gynaecol Br Commonw 1967;74:40-43.

11. Altshuler G. Some placental considerations related to neurodevelopmental and other disorders. J Child Neurol 1993;8:78-94.

12. Young SA, Crocker DW. Occult congenital syphilis in macerated stillborn fetuses. Arch Pathol LabMed 1994;118:44-

13. Ehl, S., et al. C-reactive protein is a useful marker for guiding duration of antibiotic therapy in suspected neonatal bacterial infection. Pediatrics, 1997; 99:216-21.

14. Bedside biomarkers in pediatric cardio renal injuries in emergency Noopur Singhal, Abhijeet Saha Int J Crit Illn Inj Sci. $2014 \quad$ Jul-Sep; 4(3): 238246. doi: 10.4103/2229-5151.141457 PMCID: PMC4200551

15. Biomarkers of Hypoxic-Ischemic Encephalopathy in Newborns Martha Douglas-Escobar, Michael D. Weiss; Front Neurol. 2012; 3:144. Publishedonline 2012 Nov2. doi: 10.3389/fneur.2012.00144 PMCID: PMC3486976

16. Cost of Neonatal Intensive Care in a Tertiary Care Center :Anil Narang, P.S Sandesh Kiran and Praveen Kumar, Indian Pediatrics 2005; 42:989-997. 